SCIREA Journal of Sociology
http://www.scirea.org/journal/Sociology

February 10, 2022

SCIREA

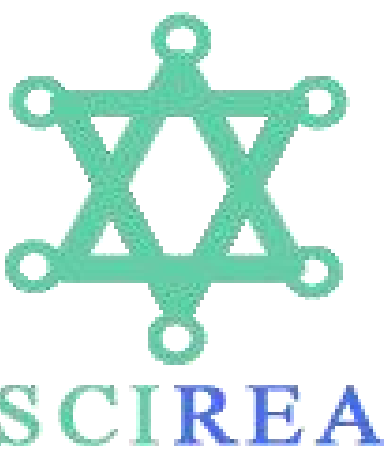

Volume 6, Issue 1, February 2022

https://doi.org/10.54647/sociology84605

\title{
A systems thinking approach for eliciting mental models in ethnography of socionatural conflict research: smallholder farming in the Biobío River Basin, Chile
}

\author{
Riveraine S. Walters ${ }^{1}$, , Gerardo Azócar García ${ }^{2}$, José Luis Arumí ${ }^{3}$, Laura Putsche ${ }^{4}$, \\ Paul Lewin ${ }^{5}$, Allyson Beall King ${ }^{6}$, Javiera Aguayo Fuentealba ${ }^{7}$, Jae H. Ryu ${ }^{8}$ \\ ${ }^{1}$ Water Resources Program, University of Idaho, United States \\ ${ }^{2}$ Land Planning and Urban Systems Unit, Center for Environmental Sciences EULA-Chile, \\ Universidad de Concepción, Chile \\ ${ }^{3}$ Departamento de Recursos Hídricos, Facultad de Ingeniería Agrícola, Universidad de \\ Concepción; Centro de Recursos Hídricos para la Agricultura y Minería (CRHIAM), \\ Universidad de Concepción, Chile \\ ${ }^{4}$ Department of Sociology \& Anthropology, University of Idaho, United States \\ ${ }^{5}$ Department of Agricultural Economics and Rural Sociology, University of Idaho, United \\ States \\ ${ }^{6}$ School of the Environment, Washington State University, United States \\ ${ }^{7}$ Facultad de Ciences Ambientales - Universidad de Concepción, Chile \\ ${ }^{8}$ Department of Soil and Water Systems, University of Idaho, United States \\ *Correspondence
}




\begin{abstract}
As we explore the complexity of socionatures, we universally find that values, traditions, needs, narratives, perceptions, norms, priorities, and policies are always evolving and often in conflict. Thus, it is critical to investigate the mental models of individuals and communities in order to deepen understandings of behavior and decision-making. However, mental cognition is non-linear, complex, and systemic, and we argue that the suite of systems thinking tools for eliciting mental models can be expanded for qualitative research. We demonstrate the advantages of this approach through the lens of socionatural conflict for Chilean smallholder farming, including how it further enriches narrative storytelling through improved contextualization and pluralization. Smallholder agriculture is a major contributor to the export-based economy of Chile. However, the combination of broad socioeconomic and environmental change has put such strain on smallholder farmers in the south-central region, that they are being forced into selling off land parcels for residential homes. Given the specific historical, political, and cultural context of Chile and the Biobío Region, typical adaptation approaches that may be suggested in academic or professional literature are not necessarily viable for Chilean smallholder farmers. Thus, deeper and more holistic understandings of the multi-layered socionatural conflict are herein developed.
\end{abstract}

Keywords: Chile; mental models; population dynamics; smallholder farming; socionatures; systems thinking

\title{
Introduction
}

Human behavior and decision-making in socionatures are based on cognitive representations of reality, or mental models, constructed through worldviews, personal life experiences, and perceptions (Jones et al. 2011). Mental models also incorporate values, knowledge of alternative options, perceived connections to issues, and social norms (Newall et. al, 2014). However, like all models, mental models are merely abstract representations of one's understanding of reality and are always partially flawed (Winz et al. 2009). Thus, cognition of socioeconomic and environmental challenges that communities face are also based on imperfect assumptions and inferences (Hovmand 2013), therefore it is critical to understand the individual and shared mental models between and among community members, including 
mental representations of the relationships between causal factors to understand their reasoning and decision-making (Newall et al. 2014). Mental models are also often part of the systems thinking literature seeking to improve understandings of dynamic, complex systems, such as socionatures (Jones et al. 2011).

The field of systems thinking is quite broad and incorporates a variety of methods and approaches. It is generally considered to be a less reductionist way of understanding the complexity that holistically incorporates feedbacks and dynamics among social, political, economic, and environmental attributes (Cabrera et al. 2015). Systems thinking approaches focus on causal relationships, connections, boundaries, feedbacks, emergent properties, and system behavior (Beall et al. 2011, Smith 2010). Considering systems thinking related to mental models is especially important, because imperfect understandings become part of the feedbacks and can further exacerbate socionatural problems. Cabrera et al. (2008) identified four universal cognitive patterns, or mental tools, that encapsulate thinking systemically (distinctions [D], systems [S], relationships [R], and perspectives [P]). More specifically, "distinctions can be made between and among things and ideas; things and ideas can be organized into systems, in which both the parts and the wholes can be identified; relationships can be made between and among things and ideas; and lastly, things and ideas can be viewed from the perspectives of other people, things, and ideas" (Cabrera et al. 2015:535). This research applies a DSRP approach toward improving the representation of systems thinking in the elicitation of mental models.

\section{Case Study}

The Biobío River Basin (BRB) has been one of Chile's most important centers of economic development. It is one of Chile's largest basins, encompassing $24,264 \mathrm{~km}^{2}$ with a mean annual flow of $334.5 \mathrm{~m} 3 / \mathrm{s}$ (Valdés-Pineda 2014). In its lower and middle reaches, its waters provide irrigation for important forest and agricultural activities in the Valle Central (Central Valley), which lies between the Coastal and Andes Mountain Ranges. Approximately seventy percent of the BRB water withdrawals irrigate some $700 \mathrm{~km}^{2}$ of agricultural lands (Grantham et al. 2013). The Biobío Region has a Mediterranean climate which is normally characterized by seasonal precipitation concentrated in the winter between May and September, but is also heavily influenced by the Southern Oscillation, which results in periodic variability in precipitation (Valdés-Pineda 2014). Chile has already experienced the effects of climate 
change through warming and drying and a yearly rise in the snow line elevation (Hill 2012). Although rivers in the Biobío Region are mixed, snowmelt and rain-fed, climate change models have predicted an overall reduction in precipitation in the near future (Valdés-Pineda 2014). South-central Chile was also experiencing what was referred to as a "Mega-Drought" for most of the previous decade, which further exacerbated climate change impacts at the time of the fieldwork (Garraud et al. 2017).

In 2010, Chile became the only South American member of the Organisation for Economic Co-Operation and Development (OECD), and thus may be considered one of the world's elite 'developed' countries, even though it also still has the highest level of income inequality among OECD states (Funk 2012). It is also important to recognize that Chile has always had an export-based economy (Frank 1967), which currently consists almost entirely of natural resources (Hill 2013). However, difficulties with agricultural production due to climate change in the drier areas of the Biobiío Region have resulted in the abandonment of property or sale and migration to urban areas (Infante \& Infante 2013).

The Chilean Water Code recognizes irrigators that receive their water from the same river diversion infrastructure as Asociaciones de Canalistas or Irrigators' Associations (IAs) (Hill 2012). IAs manage the distribution of water for all of the users that share a canal system. These organizations are private and are focused specifically on water supply, but they typically have good relationships with municipal governments and regional representatives of federal agencies. There are three large IAs on the main portion of the Biobío River and several others on the tributaries that represent thousands of irrigators, a variety of products for domestic and international markets, and tens of thousands of hectares of irrigable land. All irrigation water users in canal systems are members of their respective IA, regardless of the type of use, so both smallholder farmers and large industrial farmers are water users in canal systems. Thus, IAs can represent a range of income levels and landowners that may live in the rural farm area or an urban area outside of the canal area. Large corporations may also own some farms and forest plantations.

The most downstream of the mainstem IAs is the Asociación de Canalistas del Canal Bio-Bio Negrete (ACCBN) (https://www.biobionegrete.cl). As such, it was a useful research site, because it was the most likely to experience issues with water availability due to the large consumptive withdrawals of the other two upstream IAs. Other factors that contributed to the selection of Negrete were the existing relationships with professors at the [University], a formalized research agreement between the [University] and ACCBN, their very well- 
organized representation structure, good data collection and record-keeping, self-published materials, and a willingness to participate among the staff. In addition, the office in the town of Negrete was also conveniently accessible via public transportation from Concepción. As shown on their website, ACCBN represents 700 irrigators and controls the main canal system (not including branches and sub-branches) over seven miles long, serving over 35,000 acres of land with irrigation water. ACCBN has a yearly meeting for all users, but the territory is also split into fifteen sectors, and each has two elected representatives that meet with the staff more frequently.

\section{Methods}

This paper presents results from the ethnography of socionatural conflicts research conducted by the lead author over eighteen months in the Biobío River Basin in Chile between 2016 and 2017. This type of ethnography research centers around conflict itself, rather than a social group, so the diverse social actors, natural resources, and their interactions and power dynamics can be explored (Little 2006). Conflict in this sense is not necessarily related to battles over environmental resources, but can also refer to conflicts over meaning, norms, resources, and knowledge (Swyngedouw \& Boelens 2018). In this sense, the socionatural "conflicts" that were the focus of this research were those between the driving forces, beliefs, and capacities of the smallholders themselves to evolve and survive with the changes that enveloped them.

Throughout the fieldwork research, interdisciplinary data was collected related to agriculture, climate, hydrology, law and policy, population dynamics, export economics, and natural disasters. Using convenience and snowball sampling methods, qualitative data sources were identified, including: unstructured interviews with smallholder farmers, IA staff and board members, local academic experts, and agriculture/water government agencies; participant observation at conferences, talks, symposia, and short courses hosted by universities, government, and international organizations; and publications of the various actors and organizations. Thus, this data could not simply be "coded" and understood from the interviews alone, but was all part of a broader context and ethnographic approach.

Following the research of Walters et al. (2019) for eliciting mental models from visual boundary objects, a modified version of content/map analysis (Carley and Palmquist 1992, Carley 1993) that integrates the DSRP theory for systems thinking was explored to elicit 
mental models for this research. Content analysis has successfully been used in previous studies to elicit participants' mental models related to socionatural contexts (Abel et al. 1998, Jones et al. 2014). However, this systems thinking elicitation of mental models (STEMM) approach expands on the content analysis theory of solely identifying the concepts and relationships found in mental models, by also demonstrating part-whole systems and perspectives, improving the suite of systems thinking tools used. With these additional elements, the type of mapping performed in previous content analysis studies was not sufficient, therefore the Plectica online application was used to create DSRP maps of mental models (www.plectica.com). Plectica, created specifically to map distinctions, systems, relationships (including directionality), and perspectives, allows for such STEMM maps to be both quantitatively and visually compared, as suggested by Carley (1993). The STEMM performed by Walters et al. (2019) using existing visual representations as the data source was a novel approach, thus expanding the application to ethnography of socionatural conflict research can also be considered novel.

This exploratory paper demonstrates this STEMM approach application to map the 'collective' mental model of one subset of the interviewees, the smallholder farmers. The interview transcripts were first analyzed and mapped based on the DSRP method (see Carley and Palmquist 1992, Carley 1993, Cabrera and Cabrera 2015, Walters et al. 2019) to identify socionatural challenges and conflicts for the smallholder community. Therefore, it was necessary first to consider whether this type of analysis would be inductive or deductive in nature. Though the lead author was certainly influenced by both inductive and deductive reasoning prior to the conversations, the process of unstructured interviews and subsequent STEMM mapping followed a generative, constructive, and inductive approach to reconstruct how the farmers conceptualized their own experiences, as described by Goetz and LeCompte (1981). The observational data, publications, and other notes and documentation were also applied to improve the understanding and provide additional context for the responses.

Interactive examples of STEMM maps are provided directly via the Plectica online platform, accessible from the notes at the end of this article ${ }^{1-4}$. The 15 smallholder farmers interviewed were from the same demographic group, as discussed in the next section, thus only themetype perspectives were identified from the transcripts for this exercise. The first step in the mapping process focused on visually representing the distinct concepts in part-whole structures, along with the various types of relationships between and among them (see Figure $^{1}$ ). Once all of the interviews were mapped, common theme-type perspectives that 
permeated most or all of the conversations were applied to the concepts, parts, and relationships (see Figure ${ }^{2}$ ). As can be seen, many concepts, parts, and relationships fall under several perspectives and can thus be considered in different ways.

The next step was to combine concepts, parts, and relationships by perspectives in separate maps to identify commonalities (see Figure ${ }^{3}$ ). In this research, less prevalent concepts, relationships, and parts were also included to pluralize the overall smallholder farmer worldview. The final step of the process was to develop a synthesized, yet holistic, STEMM Map that represented the shared mental model of the smallholder farming community concerning socionatural challenges and conflict (see Figure ${ }^{4}$ )

\section{Results and Discussion}

The following discussion highlights the key findings of this STEMM modeling process in narrative form, and provides recommendations for further study and application of the approach. The theme-type perspectives are used to navigate the main points which can be followed visually using the collective STEMM map ${ }^{4}$. The reader is encouraged to explore the links provided in the notes at the end of this article to interact directly with the STEMM maps and select the perspectives below by clicking on the 'eyeball' icon in the lower left in Plectica. Both the narrative and the collective STEMM map tell the smallholder farmers' stories, but they also provide additional context for each other, toward the emergence of a more holistic and overall synergistic understanding.

\section{Sector Representatives}

All of the sector representatives that were interviewed were men and were generally upper middle-aged or seniors. They had all been representing their respective sectors for around five years, and had many years of knowledge regarding their sector, the region, and ACCBN. Some representatives specifically spoke about the Agrarian Reform in the 1960's and how it changed their lives in both positive and negative ways. They remarked that some of their neighbors who were given land did not have their own tools or means to work it and ultimately had to sell it back to the same large plantation owners who originally owned it. These families also lived through the Coup of 1973 and the Pinochet dictatorship that led to additional land being taken away, and some of their neighbors were part of the imprisoned, tortured, executed, and "disappeared" under the heavy hand of that government. Chilean smallholders have seen their country change in many extreme ways over the years and have 
continued to adapt, with a uniquely Chilean fortitude. However, as discussed below and seen on the collective STEMM map ${ }^{4}$, the essence of the socionatural conflict experienced by the Chilean smallholders is that a broad range of drivers are now heavily stacked against them, and smallholder farming may not survive without additional intervention.

\section{Water Access/Canal Condition}

The general academic literature typically represents a certain level of conflict over water between irrigators and the hydroelectric companies that have built dams upstream in the mainstem Biobío River (see Long et al. 2017). However, water access issues have nothing to do with the dams, and in fact, the smallholders have noted an increase in water security. As one farmer explained related to the dams, "before the water was cut from the canal and the wells dried up, now they don't dry up because the water is permanent". There has also been some concern about hydropeaking, but it only seemed to affect the main gate's operation at the intake and not the water availability in the fields. As explained by another smallholder, "a change was noticed in the afternoons when the water started to go down, entering less into the intake. But they reached an agreement with the irrigators' association”.

When this research began, discussions with all three main IAs in the mainstem Biobío included large projects and funding for concrete canal lining. It was assumed this was related to a reduction in water availability from the river, increased filtration, evapotranspiration, or other climate adaptation reason. However, as it turns out, the major problem for the canals and getting water to the users at the back end of the system is a type of freshwater crustacean that burrows through the canal walls (Parastacus pugnax), flooding fields upcanal, and leaving downcanal users with less water. This is especially a problem for canal users with higher fields and variable topography because the level and head pressure can be too low. However, that has been one of the main project areas of ACCBN, and many of the farmers were speaking in past tense when they said this was an issue before the canals had concrete. The aspects of what they considered to be good water access, current problems, and how they relate can be visually seen by clicking on this perspective in the interactive version of the collective STEMM map ${ }^{4}$.

One other issue discussed in a later section is that the population has rapidly increased, and the number of people per acción (share) can now be a problem for management at the field level. ACCBN manages the water rights based on the original shares, or 15.9 liters per second that were originally allocated. Once plots were subdivided, it became the users' responsibility to share water por turno (taking turns), hook up hoses, and whatever other maintenance was 
required. Usually the farmers are quite good at working with their neighbors, but it can get out of hand. As one representative explained, "in front of my house there are more than 15 that were bought and most of them from Santiago that came here. So, this plot has about 1.2-1.3 shares of water, and there are 15 neighbors who are living within this plot. How can I give water to these houses? Here is a very complicated problem for the irrigators' association".

\section{Climate Change}

It was initially thought that the major climate change issue for smallholders would be impacts to the availability of water, especially given the decreasing snowpack. However, the available storage from the Ralco Dam Reservoir, as controversial as it may be (see Long et al. 2017), has actually made the overall water availability more consistent, despite precipitation changes. In addition, though there was a general consensus that the sun is hotter, additional evaporation from the river system, canals, or fields did not result in a noticeable decrease in water for the farmers. Instead, climate change has affected the smallholders in complex ways, both positively and negatively. By clicking on the Climate Change perspective in the interactive version of the collective STEMM map ${ }^{4}$, one can view these many complex issues, their specific "parts", and how they relate to each other, as well as their effects on crops and soil quality.

First, it is important to note that this area of Chile did not traditionally grow the most valuable export products for Chile today, such as tree fruits, berries, and grapes for vineyards (see INE 2007). The reason was primarily related to southern Chile's colder temperatures, which began south of the Biobío River, where primarily cereal crops were grown. Over the past decade, the boundary of where export crops could grow has continued to move south into the Region of Araucanía. As one farmer explained, "this is how the global climate has changed everything, everything that they had in the North we will have right here".

The negative issues with the stronger sun were universally discussed among the smallholders. In particular, certain crops can be "burnt" by the sun now, such as apples and tomatoes. A farmer explains, "the sun is much hotter, as they say now, burning. For example, there is an apple plantation here, and in the summer they put something like a sun block so that the apple does not get damaged by the sun, the sun is very strong". Furthermore, the smallholders noted that yearly heat waves were now common and could last anywhere from a few days to a couple of weeks. Such temperatures now exceed 41 degrees Celsius. Depending on the timing, the farmers noted that the strong sun has also dried out the roots and soil, or alternatively, along with warmer rains, fosters conditions for fungus to grow. Larger farms end up hanging 
black sun-blocking screens, or malla kiwi, to filter the UV, but the small farmers cannot often afford the additional technology or the labor to put it up and down with the weather.

Seasonality has also become an issue. The farmers generally described the weather in the past as more consistent from year to year. Not only do they find inter-annual variability to now be a major challenge, but migration of the planting season and precipitation regime have also caused problems. Generally, the winter planting season is now earlier, and so is the summer harvest time. However, as a Mediterranean climate, they also need to adapt to the rains starting and ending for the season. For instance, the machines cannot prepare the soil well until after the rains, and the seeds can also be washed away if there is suddenly additional rain that was unexpected. Finally, rains can dilute any fumigation for pests/weeds, as discussed below. One farmer stated, "the weather has been unstable, there has been no behavior like before, with the rains like "now it's summer", "now it's winter", "now it's spring"... like the weather's been messed up, suddenly it's raining at any time. Or suddenly there is sunshine as if we were in summer and we are still in spring".

According to the farmers, other major problems that began in the last couple of decades are pests, fungi, weeds, viruses, etc., or what they tend to group together as plagas ${ }^{4}$. One farmer mentioned 15 different varieties of weeds, while others mentioned moths, aphids, and worms that attack various crops, including fruit, vegetables, beans, and cereals. As previously mentioned, there can also be issues with fungus affecting fruit and roots of other crops. The smallholders expressed that they used to sow without pesticides and herbicides, but now not only is it always required, but they have to add more every year.

\section{Crop Evolution}

Crop Evolution is the broadest perspective in the collective STEMM map ${ }^{4}$ and centers on the agricultural products themselves and how they have or may change based on the wide variety of factors, as well as the obstacles and limitations. Most of the related concepts, including: markets, government support, climate change, labor and infrastructure requirements, costs, and soil quality have their own specific attributes and relationships. This is perhaps the perspective that demonstrates the benefit of systems thinking and applying the DSRP STEMM method the most. Any attempt to reduce the information further runs the risk of decontextualizing and/or leaving out important components and interrelations.

As previously discussed, climate change is making smallholder farming more difficult. However, several other factors drive or prevent an evolution in what smallholders can grow 
profitably. As one farmer explains, "I have been told that I could put in fruit trees, but it implies more investment, you have to be more concerned, it requires more labor, and in this area labor is complicated, they are scarce, and they are expensive because they are brought to areas where there are greater quantities of crops".

Traditionally this was a region that took pride in growing cereal crops for Chile, especially wheat. There were also many dairies, but neither is generally profitable for smallholder farmers, as discussed in the next section. One smallholder noted, "for someone who was here before that was accustomed to sowing 3-4 hectares of wheat and now can't sow it because he can't sell it, he can dedicate himself to something else, vegetables, vegetables that we are going to eat every day and it is the most that is moving".

Today, smallholders generally focus on animal breeding/livestock, animal feed crops, and vegetables. They noted several reasons for not being able to adapt to new conditions or change with the times ${ }^{4}$. Most of the smallholders discussed the expense, required investment, and how long it would take for plants to mature or become productive. There are options for government loans, but there is resistance to taking those, because they have seen many crops fail for reasons previously discussed and are concerned about paying back loans with no profit. There is also an issue of getting the crops to market. There are still unpaved roads in the area, and the small profits are eaten away with transporting to far-away markets. Finally, there are technical needs and other additional labor requirements with changing crops that require more hands, more machinery, irrigation systems, etc. Most of the seasonal workers that come in go to big farms with more crops. Local laborers can earn much more in the cities or in the mines in the North, so smallholders and their families make up almost all of the labor on their farms.

One farmer explains the general big picture, "I sell a calf and buy a thousand kilos of wheat, I have no reason to be... and I pay for my things too, because I can't either. At my age, I feel that I can't. When they start to plant, they level the ground, arrange everything with machines, I don't have the energy. I have to dedicate myself, like the old ones, to raising animals and keep myself there. I don't like to get into debt for a tractor, and if I go wrong, I could even lose the field." It is common for the farmers to have old or insufficient equipment, with no capacity to upgrade and no desire to take on debt.

Many farmers also discussed soil degradation and the concerns for the ability of the soil to produce. They generally described the soil quality as poor and requiring more fertilizer every year to produce the same yield. The older farmers remember when they used to add no fertilizer or just a little saltpeter/lime. Some recognized that the soil had been overworked 
over the years without sufficient breaks. As described by one smallholder, "now everything has to have fertilizer, and with higher doses of fertilizer, the crops, if not no. Before you sowed just like that, the land produced large quantities of seeds because they had nutrients, but now no, now everything has to be grown with machinery and fertilizers". Some farmers use the services of an agronomist and get their soil tested, especially if they are registered with local or regional smallholder agencies that provide those services (as discussed below). Others have been on the land for 60 years or more and resist such technical approaches because "we are from here".

\section{Markets}

As previously mentioned, the markets for traditional farming (i.e., cereals and dairy) are no longer viable for smallholders. Whereas large farmers may have contracts, smallholders have to find negotiators, but the price is consistently too low. There is also no local trading house where they can sell their goods. In general, the main problem with wheat and a few other crops (i.e., beans) is that countries like Argentina subsidize their farming and have not had the soil degradation experienced in Chile, so yields and quality are high, but prices are low. Whereas Chile was the breadbasket of the West Coast of the South American Spanish territories and continued that tradition through exports into the late 20th century (see for example Frank, 1967), currently the country imports most of its wheat. As explained by one smallholder, "and now the problem is the market as wheat is not profitable, it is easier to import. For us, wheat is not profitable, for the people that are sowing, except those who have 100 ha to 200 ha, but we all sow for ourselves nothing else, what we are going to use".

As shown in the collective STEMM map ${ }^{4}$, while market prices are down for traditional products, production prices are universally up. These costs include maintenance, fertilizer, seed, labor, transport, equipment (in the past, they used manual/horse-driven), animals, controlling parasites, and dealing with other pests. Vegetable crops are also difficult to sell because the smallholders compete with each other and other sectors for the buyers (referred to colloquially as gallos) that come around to purchase. There are few local markets, so they have to take vegetable crops to regional markets further away controlled by unions and run on seniority. New farmers go to the end of the line. This end of the line scenario also comes into play with feed crops (i.e., corn) because the processing plants limit how much they can take each season, so smallholders are on the clock to get their goods in before the cutoff.

Smallholder dairies declined dramatically once quality requirements such as freezing milk, were put into effect a few decades ago. Again, imports and large-holder dairies were 
mentioned as the primary sources for Chile today. Smallholders do still make a little money on artisanal cheese (quesillo and queso fresco) while raising calves for sale. As discussed below, expanding a farm to be "big enough" to be profitable is rarely possible due to the high value of land in the region for other uses.

An important aspect of markets is also the price of land and the push to sell parcels, which is covered in the next section. Overall, considering the theme of markets provides an opportunity to demonstrate the need to incorporate perspectives when considering systems thinking and mental models. One can envision the vast number of perspectives (both actors and themes) involved in the many supply chains with which these farmers interact.

\section{Population Change/Land Subdivision and Sale}

Overall the population in the ACCBN-serviced lands is aging for several reasons. Initially, the Agrarian Reform of the 1960's worked well for many smallholders who had large families that helped work the farms. However, the land was then split between 5 or 6 heirs when the original owners passed. Many of the children either sold their parcel or built a home and found work outside. Thus, many once-irrigated agricultural lands became unproductive. The smallholders overwhelmingly agreed that following that generation, the youth have not stayed in the countryside and have gone to university and/or sought employment elsewhere.

As shown in the collective STEMM map ${ }^{4}$, the farmers themselves described their work as hard on their bodies, difficult work for little pay, and inconsistent when harvests fail. Educated youth prefer to live a better life through attaining higher incomes with less work in professional careers. As one farmer explained, "our people are getting older, then like the children and all these families study now, graduate, come back with a good job elsewhere, and the only thing they want to do is come and sell what piece is theirs. And that's why the field is shrinking". Another smallholder added that, "they don't like the field, they don't want to work the land because the same old ones who were there sacrificed; they saw me getting up at 5 in the morning, going around all day watering, doing maintenance to the field".

While there is a push-pull for educated youth to move away from the countryside, there is equally a pull-push bringing older Chileans to rest and/or retire in the area, thus it is important to explore the various traits of relationships and provide additional context for systems thinking. The representatives from a majority of sectors discussed how small parcels of land ( 0.5 ha - about an acre) are being sold to outsiders who are building houses and do not work the land. As such, the populations in these sectors were noted to have doubled or tripled in the 
last 30 years. This is very attractive for Concepción and Santiago's city dwellers, as it provides a tranquil rest or retirement spot with less crime, less noise, and less pollution. Chileans see this as not only a better quality of life but also a way to live longer. As such, the value of these small plots keeps increasing rapidly. The local landowners saw the price double or triple in a year and quickly jumped from 5 million pesos (CLP) to 20 million pesos (CLP) by 2017 . As one smallholder explains, "Now the people are coming to the countryside. From Santiago they come to buy here, they buy their half a hectare, make their house and leave it there. The other day I was talking to someone who said that it was for his old age... he wants his last days to rest from the noise, the rattle".

For many smallholders, selling small parcels of their land is quite attractive. Some sell to buy a new truck, support their kids through university, or simply because they can no longer work it and renting can be too much hassle (late payments/poor treatment of property). For others, they sell because they do not have a choice. Whether they are making money or not, they still owe taxes, and the local government will eventually auction off their land if they owe too many back taxes. Instead, they will first suggest that the farmers sell to pay their bill and have some left over. It would seem that they could just sell to another farmer who would continue to make the land productive, but the market does not work like that. As explained by one farmer, "it is more profitable for them to sell small pieces of land than to sell everything in one trip. People come and pay them, for example, 15 million for half a hectare. They make their house to their liking, and they settle there on half a hectare, but if they sell the whole plot, they won't give them more than 4 or 5 million per hectare. So people are selling it that way by the piece."

With the market this way, it is impossible for farmers to expand or for those doing well to buy land from their neighbors to continue growing. One representative expressed that "if I want to buy 2-3 hectares, I have to have a pile of money, and I don't. So the ideal thing for me would be that nobody would sell, or if I could buy from our people, that they sold to us, but they can't because of the money. And that's why people come from outside with lots of money". The smallholders generally feel that they will eventually all disappear, and there will only be big farms and houses.

\section{Government Support}

There are agencies at both the federal and local levels that help smallholder farmers. Over half of the representatives had good things to say about Instituto Nacional de Desarrollo Agropecuario (INDAP) or the Agricultural Development Institute (INIA) both from the 
Ministry of Agriculture. As shown in the collective STEMM map 4 , there are many "parts" to government support, as they provide services such as agronomist advice, soil quality analysis, veterinarians, loans/credit, limited free seed/fertilizer mix, community programs, talks, and workshops. The focus of INDAP is generally to help smallholders increase productivity, but they are also trying to help keep irrigated land productive. As one smallholder explained, "the government is interested in keeping people on their land and decreasing migration to the cities. In the cities, they generate pockets of poverty when there is a lot of migration from the countryside to the cities, so they are trying to give farmers a bonus to keep them on their land. There's a kind of redistribution of income that way. The copper from the big businessmen to the farmers to maintain a stable agricultural activity". At the local level, the smallholders also have access to PRODESAL, or the Local Development Program, which is a collaboration between INDAP and 'executing entities' (i.e., municipalities and other public/private entities). PRODESAL members also receive additional benefits, and problems are also shared with INDAP.

The representatives mentioned several challenges with working with these government programs. First, to be registered, one needs to have the deed to the land, which was not necessarily formally separated when the land was passed down, so a deed may still include the land of several people. Another major issue for getting support is that smallholder farmers did not necessarily have many years of formal education, and the application paperwork can be quite cumbersome. In addition, when INDAP gives credit, it is a one-year loan, so many of the farmers have had to take it every year and thus have been in debt for many years. Finally, these programs have to prioritize, so sometimes smallholders are left waiting long periods for a project to be supported. One representative explained that he had been requesting a loan for several years to purchase some small equipment that would improve his yield and productivity immensely, but the funds were never there for him. In his words, "the small farmer can die and the needs do not arrive, and we are all the same here in Negrete, and that's why the small farmer comes to sell, because the taxes eat them up. They start to get saturated because there's nowhere to get the taxes".

\section{Synthesis \& Conclusions}

This paper demonstrates the usefulness of broadening traditional content analysis mental models elicitation methods to incorporate the additional systems thinking tools that have been identified by the work of Derek Cabrera and others. The collective STEMM map ${ }^{4}$ presents the 
tight interconnectivity of the many elements of socionatural conflict identified from the mental models of the smallholder farmers in Chile. Applying our STEMM method, we highlighted the usefulness of including parts and wholes in order to pluralize, contextualize, and avoid being overly reductionist with the interview data. It is important to understand the various aspects and nuances that different individuals and groups incorporate in their mental models in order to produce a more holistic understanding of their socionatural decisionmaking and behavior. In addition, we were able to describe and provide characteristics of relationships rather than simply identifying the direction, polarity, and strength indicators that other models use. Finally, even within this specific group of interviewees, many theme-type perspectives were expressed that overlapped the concepts that they discussed, which showed the value of including perspectives even among one demographic group. Additional subject perspectives could also be broken out of this group, depending on the farmer, sector, croptype, distance from the river, soil quality, or other factors desired by the user and intent of the research.

The overall ethnography of socionatural conflict approach allowed for sufficient additional context to be gained in order to produce meaningful outcomes. However, future research with the DSRP STEMM process could include a participatory process to clarify, expand, and give additional context to collective STEMM maps, such as those created for this research ${ }^{1-4}$. Given the often outsider positioning of researchers, such community-based mapping can improve understandings even further. The research also established that not only can interviews and other qualitative data be mapped from the discourse on the ground, but that it is also simple to enhance those maps through the weaving of the subjects' narrative stories and direct quotes. Thus, one can easily pass back and forth from narratives to STEMM maps in a synergistic process of creation and evolution that mirrors both the complexity and impermanence of socionatural relationships.

\section{Notes}

1. Figure A1.1 is available interactively at: https://www.plectica.com/maps/5H15FS6R4

2. Figure A1.2 is available interactively at: https://www.plectica.com/maps/8QFSFCJCP

3. Figure A1.3 is available interactively at: https://www.plectica.com/maps/5DKQZ18EL

4. Figure A1.3 is available interactively at: https://www.plectica.com/maps/BLXY4EYUX 


\section{References}

[1] Abel, N., H. Ross, and P. Walker. 1998. "Mental models in rangeland research, communication and management." Rangeland Journal 20:77-91. https://doi.org/10.1071/RJ9980077

[2] Beall, A., F. Fiedler, J. Boll, and B. Cosens. 2011. "Sustainable Water Resource Management and Participatory System Dynamics. Case Study: Developing the Palouse Basin Participatory Model.” Sustainability 3(12):720-742. https://doi.org/10.3390/su3050720

[3] Cabrera, D., and L. Cabrera. 2015. Systems thinking made simple: new hope for solving wicked problems. Odyssean, Ithaca, New York, New York, USA

[4] Cabrera, D., L. Cabrera, and E. Powers. 2015. "A unifying theory of systems thinking with psychosocial applications." Systems Research and Behavioral Science 32:534-545. https://doi.org/10.1002/sres.2351

[5] Cabrera, D., L. Colosi, and C. Lobdell. 2008. "Systems thinking." Evaluation and Program Planning 31:299-310. https://doi.org/10.1016/j.evalprogplan.2007.12.001

[6] Carley, K. 1993. "Coding choices for textual analysis: a comparison of content analysis and map analysis.” Sociological Methodology 23:75-126. https://doi.org/10.2307/271007

[7] Carley, K., and M. Palmquist. 1992. "Extracting, representing, and analyzing mental models." Social Forces 70:601-636. https://doi.org/10.1093/sf/70.3.601

[8] Frank, A. G. 1967. Capitalism and underdevelopment in Latin America. Monthly Review Press, New York, USA.

[9] Funk, K. 2012. ““"Today There Are No Indigenous People” in Chile?: Connecting the Mapuche Struggle to Anti-Neoliberal Mobilizations in South America." Journal of Politics in Latin America 4(2):125-140. https://doi.org/10.1177/1866802X1200400205

[10] Garreaud, R., C. Alvarez-Garreton, J. Barichivich, J. P. Boisier, D. Christie, M. Galleguillos, C. LeQuesne, J. McPhee, and M. Zambrano-Bigiarini. 2017. "The 20102015 mega drought in Central Chile: Impacts on regional hydroclimate and vegetation." Hydrology and Earth System Sciences Discussions:1-37. https://doi.org/0.5194/hess2017-191

[11] Goetz, J. P., and M. D. LeCompte. 1981. "Ethnographic Research and the Problem of Data Reduction." Anthropology \& Education Quarterly 12(1):51-70. https://doi.org/10.1525/aeq.1981.12.1.05x1283i 
[12] Grantham, T. E., R. Figueroa, and N. Prat. 2012. "Water management in mediterranean river basins: a comparison of management frameworks, physical impacts, and ecological responses." Hydrobiologia 719(1):451-482. https://doi.org/10.1007/s10750-012-1289-4

[13] Hill, M. 2012. Climate Change and Water Governance, Adaptive Capacity in Chile and Switzerland. Springer Science \& Business Media. doi:10.1007/978-94-007-5796-7.

[14] Hill, M. 2013. "Adaptive Capacity of Water Governance: Cases From the Alps and the Andes." Mountain Research and Development 33(3):248-259. http://doi.org/10.1659/mrd-journal-d-12-00106.1

[15] Hovmand, P. S. 2013. Community Based System Dynamics. Springer Science \& Business Media. http://doi.org/10.1007/978-1-4614-8763-0

[16] Infante, A., and F. Infante. 2013. "Percepciones y estrategias de los campesinos del Secano para mitigar el deterioro ambiental y los efectos del cambio climático en Chile." Agroecología 8(1):71-78. https://revistas.um.es/agroecologia/article/view/183001

[17] Jones, N. A., H. Ross, T. Lynam, P. Perez, and A. Leitch. 2011. "Mental models: an interdisciplinary synthesis of theory and methods." Ecology and Society 16(1):46. https://doi.org/10.5751/ES-03802-160146

[18] Jones, N. A., H. Ross, T. Lynam, and P. Perez. 2014. "Eliciting mental models: a comparison of interview procedures in the context of natural resource management." Ecology and Society 19(1):13. https://doi.org/10.5751/ES-06248-190113

[19] Little, P. E. 2006. "Ecologia política como etnografia: um guia teórico e metodológico." Horizontes Antropológicos 12(25):85-103. https://doi.org/10.1590/S010471832006000100005

[20] Long, J.A., S. Hirsch, and J. Walters. 2017. "Chile, the Biobío, and the Future of the Columbia River Basin." Idaho Law Review 53(1):239-285. https://digitalcommons.law.uidaho.edu/idaho-law-review/vol53/iss1/7

[21] Newell, B. R., R. I. McDonald, M. Brewer, and B. K. Hayes. 2014. "The Psychology of Environmental Decisions." Annual Review of Environment and Resources 39(1):443-467. https://doi.org/10.1146/annurev-environ-010713-094623

[22] Smith, T. 2010. "Using critical systems thinking to foster an integrated approach to sustainability: a proposal for development practitioners." Environment, Development and Sustainability 13(1):1-17. https://doi.org/10.1007/s10668-010-9243-y

[23] Swyngedouw, E., and R. Beolens. 2018. “"...And Not a Single Injustice Remains": Hydro-Territorial Colonization and Techno-Political Transformations in Spain.” In Water Justice, edited by R. Boelens, T. Perreault, and J. Vos. Cambridge University Press. 
[24] Valdés-Pineda, R., R. Pizarro, P. García-Chevesich, J. B. Valdés, C. Olivares, M. Vera, F. Balocchi, F. Pérez, C. Vallejos, R. Fuentes, A. Abarza, and B. Helwig. 2014. "Water governance in Chile: Availability, management and climate change." Journal of Hydrology 519:2538-2567. http://doi.org/10.1016/j.jhydrol.2014.04.016

[25] Walters, R. S., E. S. Kenzie, A. E. Metzger, W. J. Baltutis, K. B. Chakrabarti, S. L. Hirsch, and B. K. Laursen. 2019. “A systems thinking approach for eliciting mental models from visual boundary objects in hydropolitical contexts: a case study from the Pilcomayo River Basin.” Ecology and Society 24(2):9. https://doi.org/10.5751/ES-10586240209

[26] Winz, I., G. Brierley, and S. Trowsdale. 2009. "The use of system dynamics simulation in water resources management." Water Resources Management 23:1301-1323. https://doi.org/10.1007/s11269-008-9328-7 